\title{
Mass-length allometry covaries with ecosystem productivity at a global scale
}

\author{
Dolores Ruiz-Lupión (iD ｜ José María Gómez (iD ｜ Jordi Moya-Laraño
}

Department of Functional and Evolutionary Ecology, Estación Experimental de Zonas

Áridas, EEZA-CSIC, Almería, Spain

\section{Correspondence}

Dolores Ruiz-Lupión, Department of Functional and Evolutionary Ecology, Estación Experimental de Zonas Áridas, EEZA-CSIC, Carretera de Sacramento s/n, Almería, 04120, Spain.

Email: loli.ruiz@eeza.csic.es, loli.ruizlupion@ gmail.com

\section{Funding information}

Ministerio de Educación, Cultura

y Deporte, Grant/Award Number:

FPU13/04933; Consejo Superior de Investigaciones Científicas, Grant/ Award Number: CGL2014-61314-EXP and CGL2015-66192-R; Consejería de Economía, Innovación, Ciencia y Empleo, Junta de Andalucía, Grant/Award Number: P12-RNM-1521

Editor: Alberto Jiménez-Valverde

\begin{abstract}
Aim: It is still debated whether allometry, the relationship between body size and body parts, entails merely an evolutionary constraint or can itself evolve. Recently, a hypothesis has been proposed that states that static allometry (allometry measured across individuals at the same developmental stage) can evolve from differences in the developmental pathways between pairs of traits under different nutritional environments. A macroecological prediction stemming from this hypothesis is that allometric coefficients (scaling and allometric factors) should covary with ecosystem productivity. Here, we tested this prediction using a worldwide database of masslength allometric equations.

Location: Worldwide, data distributed across the entire globe.

Time period: 1967-2017.

Major taxa studied: Soil arthropods.

Methods: We fitted general linear models with the allometric coefficients (the scaling $a$ and allometric $b$ factors) as the dependent variables. The target independent variable was the normalized difference vegetation index, as a proxy of ecosystem productivity. Longitude, absolute latitude and altitude, as well as mean annual temperature and mean annual precipitation were included as both covariates and additional variables of interest. We also included body bauplan (obtained from geometric morphometrics), taxonomic affiliation (a proxy of phylogenetic relationships) and the reciprocal allometric coefficient as covariates in the model.

Results: We found a strong negative association between both allometric factors and the productivity of the ecosystems, and the effect for the allometric factor $b$ was stronger at lower trophic levels. We also detected strikingly similar effects of geographic and climatic predictors on both allometric factors, suggesting the occurrence of similar selective regimes.

Main conclusions: The fact that productivity, geography and climate affect the value of mass-length allometric coefficients has important consequences not only to understand the evolution of allometries, but also for how energy is processed in soil ecosystems across the globe.
\end{abstract}

\section{KEYWORDS}

allometry evolvability, body energy storage, climatic gradient, ecosystem productivity, masslength allometry, soil arthropods, space gradient 


\section{1 | INTRODUCTION}

Allometry refers to the scaling relationship between two body parts among individuals. It can be estimated among individuals within the same developmental stage and species, typically adults (static allometry), among developmental stages within the same or different individuals (ontogenetic allometry), or among individuals within the same developmental stage, usually also adults, but belonging to different taxa (evolutionary allometry). This relationship is described by a power function with form $y=a x^{b}$ relating the trait $x$, usually body size, with the trait $y$ through the scaling factor $a$ and the allometric factor $b$ (Cock, 1966; Gould, 1966; Huxley, 1932; see Supporting Information Appendix S1; a list of references for the Supporting Information appendixes, figures and tables is found in Appendix 1: References of Supporting Information). Whether static allometries remain more or less fixed and constrain the evolution of phenotypic diversity has been hotly debated in evolutionary biology (Gould, 1977; Huxley, 1932; Lande, 1979; Maynard-Smith et al., 1985). However, recently the constraint hypothesis has been dismissed to some extent, as several empirical studies have concluded that there is evolvability in static allometry by showing that allometry coefficients respond to natural selection (Pélabon et al., 2014; Shingleton, Frankino, Flatt, Nijhout, \& Emlen, 2007; Stillwell, Shingleton, Dworkin, \& Frankino, 2016; Voje \& Hansen, 2012). Therefore, because scaling and allometric factors differ across taxa, this may provide evidence that static allometry can evolve. At microevolutionary time-scales, on the other hand, the evolution of allometry can only occur in the absence of developmental constraints (Frankino, Zwaan, Stern, \& Brakefield, 2005). Indeed, microevolutionary studies suggest that the evolvability of the allometric factor (i.e., evolution of the allometry sensu stricto) is much lower and less efficient relative to the evolvability of the scaling factor (i.e., evolution sensu lato) (Bolstad et al., 2015; Egset et al., 2012; Owen \& Harder, 1995; Tobler \& Nijhout, 2010).

A recent theoretical approach has linked the proximate mechanisms leading to static allometry to the evolution of allometry (Shingleton et al., 2007). This approach shows how the differences in the developmental reaction norms of body size and any other trait covarying with it can explain whether static allometries are isometric or deviate from isometry. This mechanism then will constrain the shape of evolutionary allometries and thus the evolution of allometry itself. In arthropods, nutritional regulation of insulin-like growth factor (IGP) have been shown as one of the most important mechanisms to shape body size and related trait reaction norms (Emlen, Warren, Johns, Dworkin, \& Lavine, 2012; Shingleton et al., 2007).

Given the above tenets, we predict that the amount of energy available in ecosystems will influence the magnitude of allometry (the scaling and allometric factors) through affecting the nutritional status of organisms during development. Furthermore, long-term (i.e., at evolutionary time-scales) persistent differences in energy availability across ecosystems should promote the evolution of static or evolutionary allometries in a manner consistent with the idea that differences in nutritional reaction norms between body size and other traits have become constitutive over evolutionary time. Alternatively, these reaction norms could still be at work and the same pattern could arise from phenotypic plasticity if identical genotypes would respond differently depending on the energy available in ecosystems. In either case, whether from a constitutive, evolutionary response or from a plastic, ecological response, an association between energy and allometry would be expected.

Here, we test the above hypothesis by deciphering if mass (M)-length (L) allometric in soil arthropods covary with the energy available in the ecosystem. Although mass is an unconventional trait to use in allometry, one can see mass-length relationships as integrative allometries, as the scaling of mass with body length could rule the scaling of any other organ with body length, being therefore of central importance. Indeed, mass-length allometries have been included in comparative studies about the evolution of allometry before (e.g., Voje, Hansen, Egset, Bolstad, \& Pélabon, 2014). Our test is based on the assumption that higher primary productivity is linked to higher rates of litter accumulation in soils and that there is an indirect bottom-up effect of primary productivity on soil productivity (Capellesso et al., 2016); in other words, more plant material being dropped on the ground results in more energy being available for soil fauna. In particular, we predicted that in highly productive environments selection should favour length over mass (lower allometric coefficients) because growth should be favoured over energy storage (Ficetola et al., 2010; Olalla-Tárraga \& Rodríguez, 2007; Valenzuela-Sánchez, Cunningham, \& Soto-Azat, 2015). To evaluate this hypothesis, we analysed the relationship between productivity and the scaling and allometric factors of the mass-length allometric equations built for soil arthropods in many localities all over the world. The information was retrieved both from allometries estimated by the authors as well as from a comprehensive bibliographic review. Because the data were heterogeneous, we controlled for possible confounding effects by including in all analyses not only the allometric variables but also the geographic location, as well as the major climate variables (mean annual temperature and precipitation) of each study site. These variables can influence allometry independently of ecosystem productivity. We here assume that a lower value of the allometric factors may be a sign of selection favouring faster development (or growth rate in length), instead of favouring energy storage or investment in other body structures (Dmitriew, 2011). This even applies to the scaling factor $a$, as for instance, when length is measured in millimetres, this coefficient is an estimate of the body mass of animals that are $1 \mathrm{~mm}$ in length (White \& Gould, 1965; see Supporting Information Appendix S1). As most animals in our database are adults at a body length $>1 \mathrm{~mm}$ (see Supporting Information Table S1), a low value of a may be a sign that the next instar (i.e., growing above $1 \mathrm{~mm}$ in length) could be attained relatively fast after accumulating relatively less energy. Because the normalized difference vegetation index (NDVI) could affect each type of allometry differently (static versus ontogenetic versus evolutionary - see Supporting 
Information Appendix S1), we included such information in the analysis. In addition, mass-length allometry may also depend on the phylogenetic relationship among taxa, the body bauplan or shape variation and the different trophic habits that may indicate different body compositions, body masses and body densities of the different arthropod taxa included in the study. Hence, we also included the taxonomic affiliation, the morphological body bauplan and the feeding habits or trophic level (low trophic level: decomposers plus herbivores; higher trophic level: omnivores plus predators) of the arthropods for which each equation was estimated.

In this study, we found a significant and negative relationship between the primary productivity of each locality and the allometric factors, and the effect on the allometric factor $b$ was stronger at higher trophic levels. Moreover, differences in body shape had relevant effects on the allometric coefficients. We also found relevant negative relationships between the scaling and allometric factors and some of the geographic and climatic predictors, indicative of selection favouring faster development. These findings have important ecological consequences, as these documented differences in allometry may be an indication of how energy is processed differently by the soil fauna in different parts of the globe and different climates, with possible implications for abundance-body mass relationships and the energetic equivalence rule (Damuth, 1981).

\section{2 | MATERIALS AND METHODS}

\subsection{Database}

We compiled a database containing information on the relationships between mass and length of individuals from six main groups of soil invertebrate arthropods: Arachnida, Chilopoda, Diplopoda, Entognatha, Insecta and Isopoda (see Supporting Information Table S1). This information was obtained both from the literature and from our own field sampling (see Supporting Information Appendix S2, Table S2). All studies included in the database estimated length as the total body length of the arthropod without appendages, which, according to how it is measured, is a homologous trait across all the studied taxa (Figure 1). In total, the database included 283 mass-length relationships (equations hereafter) from 45 georeferenced sites located all over the world, from the equator to high latitudes, and from many disparate biomes (Figure 2, see Supporting Information Table S3); a list of the data sources is found in Appendix 2: Data sources. The most intensely sampled arthropods
ORDER

Chilopoda

Acari

FIGURE 1 Schematic representation of how body length was measured for each arthropod group included in this study. Homologous traits are represented by dark blue circles. Total body length was estimated as the length of the solid dark blue lines connecting these homologous traits and excluding appendages. The black scale bars next to each animal are orientative to compare dimensions among the main taxa, as the drawings correspond to just any random adult individual within the group in terms of body length [Color figure can be viewed at wileyonlinelibrary. com]
CLASS

ORDER

CLASS

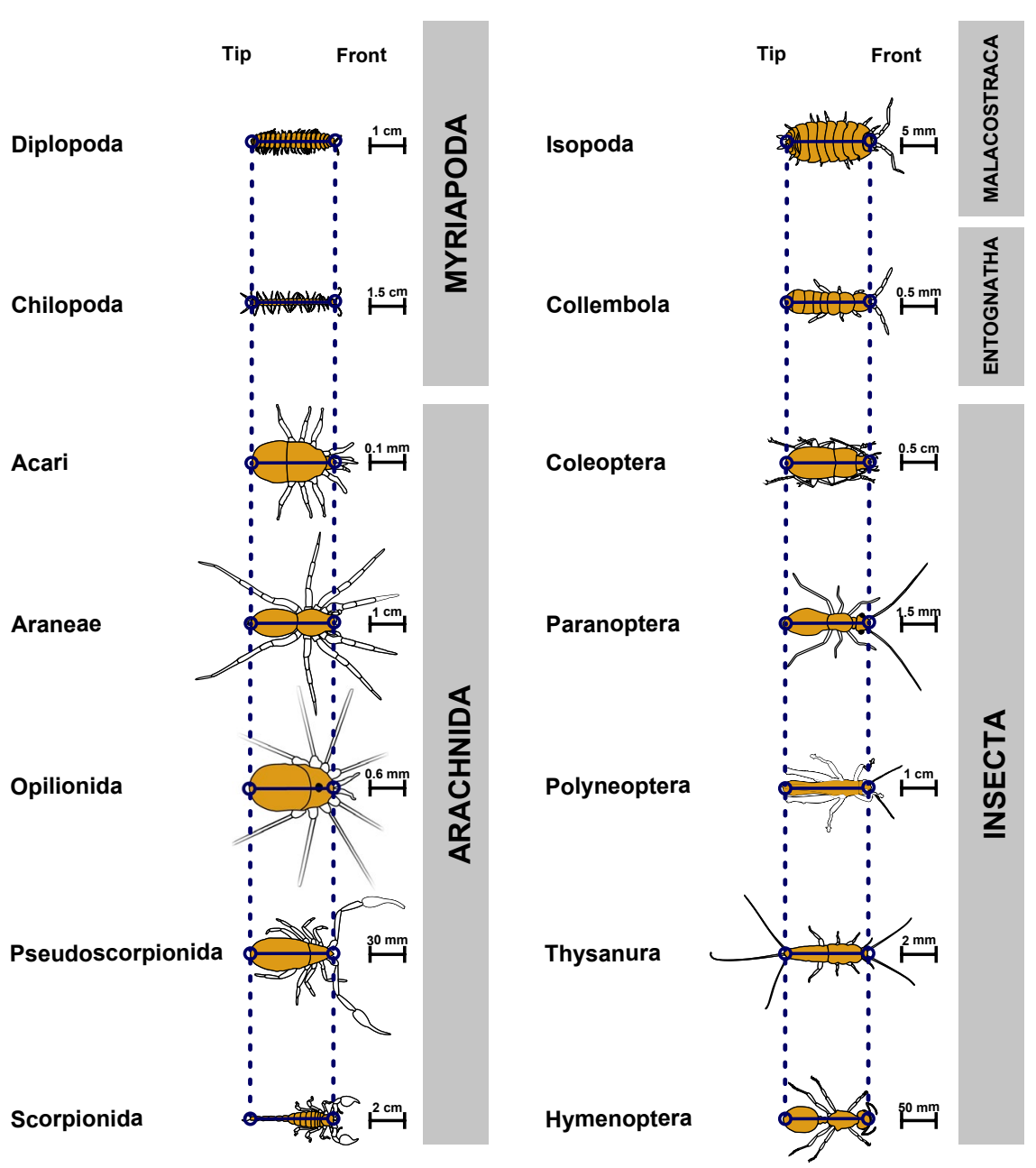




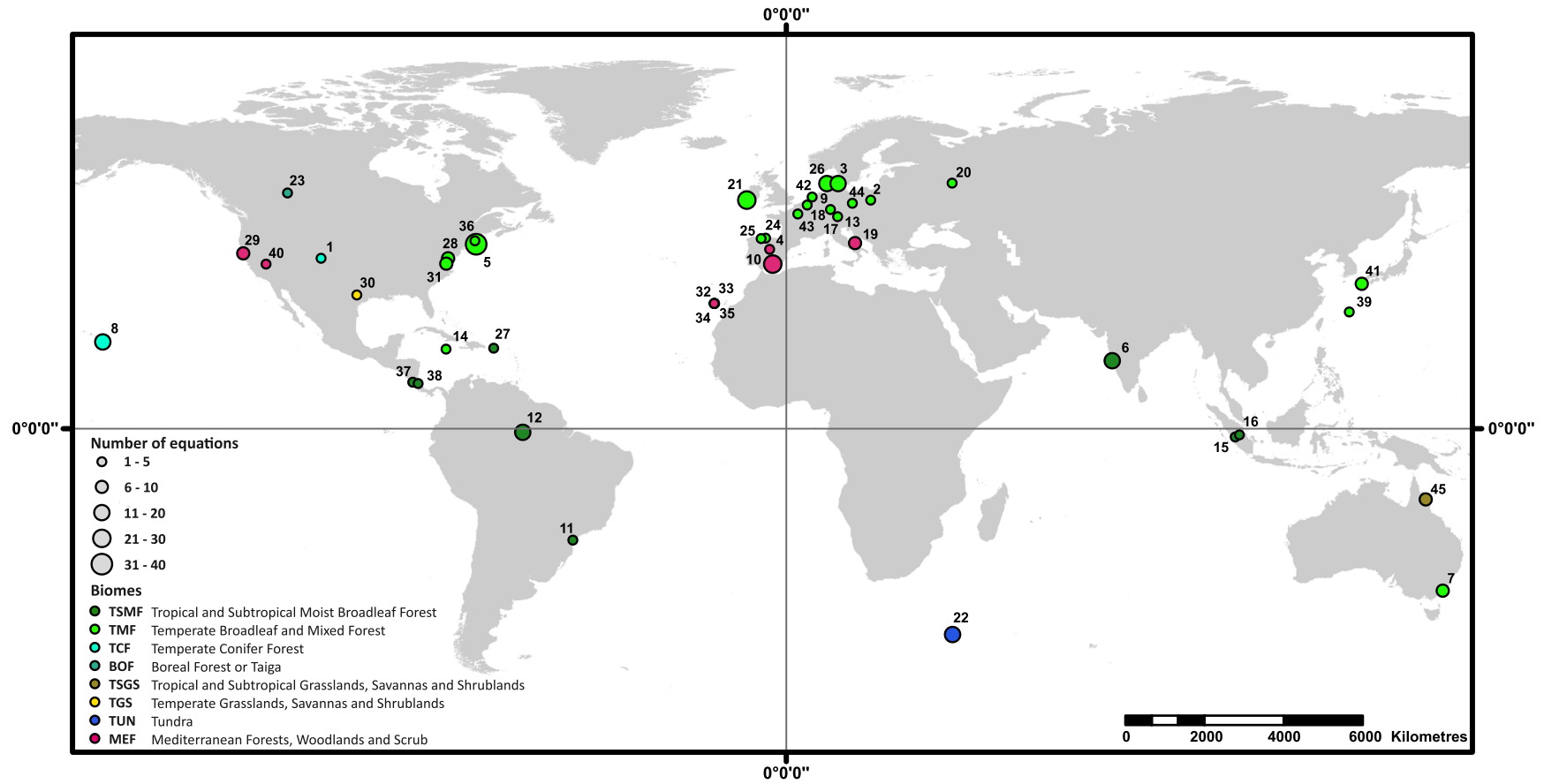

FIGURE 2 Global distribution of the mass-length allometry dataset. The number by each dot denotes the site/study as coded in the dataset (see Supporting Information Table S3). Each colour represents the type of environment according to the ecological classification system developed by the World Wildlife Fund (WWF), available in https://www.worldwildlife.org/biomes, in which the major habitat types, similar to biomes, were identified. The size of the dot indicates the number of equations in each locality [Color figure can be viewed at wileyonlinelibrary.com]

were Arachnida (112 equations) and Insecta (102 equations) (see Supporting Information Table S2). Because sample size usually affects the accuracy of the estimates, we included in the database only those equations that included information on sample size, of which only $66 \%$ contained information on the standard errors of the $a$ and $b$ estimates.

\subsection{Handling the scaling factor $a$ and allometric factor $b$}

Because of the high heterogeneity in how different works presented the equations, we retrieved the scaling factor $a$ and allometric factor $b$ from each of these 283 equations differently. Therefore, when necessary we transformed the original equations to convert all of them to power functions (see Supporting Information Appendix S3), which only occurred in 10 of the data points. In particular, no transformation was performed when the original equations were already power functions (31 cases), whereas back-transformation was performed when the original equations were log-log fits on either base $e$ or base 10 (215 cases). New power fits were performed by means of nonlinear regression in the R function "nls" when the data were available (27 cases, see Supporting Information Table S4). Despite the fact that Model II regression could be desirable for the purpose of our study (LaBarbera, 1989, but see Hansen \& Bartoszek, 2012), in order to make the database as homogeneous as possible, and for consistency across studies, in the cases in which we had the original datasets we also estimated the allometric exponents by means of Model I ordinary least squares (OLS) regressions (see Supporting Information Appendix
S4). Transformations that are more sophisticated were necessary when equations were provided as semi-logarithm functions, polynomial functions or square-root functions (see Supporting Information Table S4). We tested the accuracy of the transformations by comparing the original equations to the transformed ones. We only needed to transform the equations in a very small proportion of the cases (3.5\%), and the proportion of variances explained by the newly constructed equations on the older ones ranged between 93 and 100\%, indicating very low error (see Supporting Information Figure S1, Table S5). The scaling factor $a$ was also transformed appropriately to allow comparisons across equations (see Supporting Information Appendix S3).

\section{3 | Estimation of primary productivity}

We estimated primary productivity for each of the sites by means of the NDVI (Verdin, Pedreros, \& Eilerts, 2003), which is a proportion of a difference (difference-sum ratio) and has therefore no units. NDVI varies between -1.0 and +1.0. Negative values away from zero correspond to water bodies (e.g., oceans, lakes), while negative values close to zero correspond to areas of rock, sand or snow. Positive values correspond to vegetation (.2-.4 shrub and grassland, > .8 temperate and tropical rainforests; Weier \& Herring, 2000). We obtained the values of NDVI for each georeferenced site from the website of Global Agricultural Monitoring, available in https://glam1.gsfc.nasa.gov/, that provide information of Global Inventory Modeling and Mapping Studies (GIMMS) of the National Aeronautics and Space Administration (NASA). To ensure that the data were comparable among sites, we downloaded a NDVI temporal series for each $0.25^{\circ}$ cell from the MODIS sensor 
(Moderate-Resolution Imaging Spectroradiometer) in the Terra satellite, and calculated the average NDVI among years for each site (time window: 2000-2016; Weier \& Herring, 2000).

\subsection{Climate variables}

The relationship between the allometric factors and productivity can be masked by the same climate variables that influence the NDVI (e.g., water availability, temperature). For this reason, we controlled for the climate of each location in all the models. The climate of each location was described by two widely used variables, the mean annual temperature (MAT) and the mean annual precipitation (MAP). Climate data were downloaded from WorldClim-Global Climate Data, a free accessible climate database for ecological modelling, available in https:// www.worldclim.org/. We used GIS version 1.4 for current conditions $(\sim 1950-2000)$ with a 30 arc-seconds $\left(1 \mathrm{~km}^{2}\right)$ resolution. This database contains 19 bioclimatic variables (codes $\mathrm{BIO}_{1}$ to $\mathrm{BIO}_{19}$ ) derived from the monthly mean, minimum and maximum temperature and monthly precipitation values that are transformed into biologically meaningful variables. The altitude of each locality was also obtained from the above database. The data layers were generated through interpolation of average monthly climate data obtained from those weather stations for which there were records for at least 10 years (max. 30 years: 1960-1990). In some cases, the time period extended to the range 1950-2000 to increased the number of records for some areas (Hijmans, Cameron, Parra, Jones, \& Jarvis, 2005). The extraction of data was accomplished by the use of the Shuttle Radar Topography Mission or SRTM elevation database of NASA (Farr et al., 2007) and the ANUSPLIN software package version 4.3 (Hutchinson, 2004), a program that interpolates multivariate data using plate smoothing splines (latitude, longitude and altitude as independent variables).

\section{5 | Phylogenetic relationships among the arthropods included in the study}

Allometry may also depend on the phylogenetic relationships among the taxa included in the study (i.e., phylogenetic signal). Due to the idiosyncrasy of each study, and the variability in the level of taxonomic accuracy for which equations were built, no phylogeny was available to account for phylogenetic distances. Thus, in order to partially control for this potential source of pseudoreplication, the taxonomic group common to all studies, class, was considered an accurate proxy of the phylogenetic relationships of the studied arthropods. A similar approach has been previously used in other comparative studies in macroecology (Clutton-Brock \& Harvey, 1977; Ehnes, Rall, \& Brose, 2011; Hadfield \& Nakagawa, 2010).

\section{6 | Body bauplan of the arthropods included in the study}

Our equations were built for many different groups of arthropods having very different body bauplans. As the value of the mass-length allometric relationship probably depends on the bauplan of the arthropod taxa, which is an important factor of shape variation (Outomuro \& Johansson, 2017), we used geometric morphometrics to describe body shape as a proxy of the bauplan for each arthropod group considered in this study, and used the principal components obtained from the analyses as covariates (principal components of body bauplan or PCGMs) to control for shape in the regression models. Geometric morphometrics is a tool to summarize the shape of organisms by the use of landmark points, which we assigned following the arthropod homologies on their tagmosis. A Procrustes fit standardize all the information about size, position and orientation, resulting in variables that explain different aspects of the shape of the animal, and as they are comparable, can then be further submitted to interpretation and analysis and used to make inferences about shape (Zelditch, Swiderski, \& Sheets, 2012; see Supporting Information Appendix S5, Figures S2 and S3). In addition to landmarks, pseudo-landmarks were considered so as to increase the chances to grasp the shape of body condition across all taxa (e.g., abdomen expanding with food acquisition in spiders; Jakob, Marshall, \& Uetz, 1966; see Supporting Information Appendix S5, Figure S4). This procedure of shape analysis was performed using pictures for the 51 families and 13 orders of arthropods included in our dataset (see Supporting Information Appendix S5, Figure S5). Using a principal components analysis, we obtained the first three components, which explained together $96.2 \%$ of the variance in shape. The first component (PCGM1) was interpreted as body slenderness with reduction of cephalic area (e.g., a high value of PCGM1 are represented by the Myriapoda taxonomic group), the second (PCGM2) was associated with a change in body thickness (e.g., Opilionida) and the third (PCGM3) was associated with a change in relative abdomen volume (e.g., Pseudoscorpionida) (see Supporting Information Appendix S5, Figure S6).

\section{7 | Feeding habits of the arthropods}

Different trophic habits (decomposer, herbivore, omnivore or predator; see Supporting Information Appendix S6, Figure S7a) entail different stoichiometry compositions (Fagan \& Denno, 2004; Jakob et al., 1966; Raubenheimer, Simpson, \& Mayntz, 2009), with predators having lower $\mathrm{C}: \mathrm{N}$ than herbivores (Fagan et al., 2002; Fagan \& Denno, 2004; Raubenheimer et al., 2009). As different body compositions may lead to different body masses and even densities (Moya-Laraño, Macías-Ordóñez, Blanckenhorn, \& Fernández-Montraveta, 2008), and this in turn could affect the relationship between the environmental variables and allometry, we also considered a variation of the final model that included the interaction between feeding habits and NDVI. In that respect, we anticipated that the effect of productivity on allometry could dampen or disproportionally increase from lower (herbivores, decomposers) to higher trophic levels (predators, omnivores) (see Supporting Information Figure S7b).

\section{8 | Types of mass-length allometry equations}

The database included a mixture of static (19 studies), ontogenetic (49 studies) and evolutionary allometries (215 studies) (see Supporting 
Information Appendices S1 and S7, Figure S8a,b), which may be subject to different evolutionary constraints (Klingenberg, 1998; Reiss, 1989; Voje et al., 2014). In order to test if the NDVI could differently affect each of these types of allometries, we included the type of allometry (static, ontogenetic or evolutionary) as a categorical variable for analysis and its interaction with NDVI. If, as suggested by Voje et al. (2014), different types of allometry could follow similar trajectories, then we could expect no interaction between the type of allometry and the environmental factor. If an interaction was found, we then re-ran the models including only the data for evolutionary allometries, as this was the only one with sufficient sample size ( $n=$ 215) to allow fitting all the covariables to finally testing NDVI. Some more details are provided in the next section.

\section{9 | Statistical analysis}

We ran four nested general linear models for each of the two allometric factors after checking that there are no significant correlations between the target variables (see above), except those we expected between latitude and both MAT and MAP $(r=.85$ and $r=$ .59, respectively; see Supporting Information Table S6):

1. The first model, or Base model, included the reciprocal factors ( $a$ for testing $b$, and $b$ for testing $a$ ), the class of the arthropods and the target variable NDVI (see Supporting Information Tables S7 and S8). The reciprocal factors were included because the factors $a$ and $b$ can be strongly negatively correlated with each other by geometric constraints alone (White \& Gould 1965), and indeed they were in our database (see Supporting Information Appendix S8, Figure S9). This allowed testing for the effect of environmental factors on $a$, regardless of the length and mass ranges of the animals included to estimate $a$ in the different studies. Class was considered as a fixed factor because it had fewer than 10 categories (Zuur, leno, Walker, Savaliev, \& Smith, 2009). To test for spatial autocorrelation, we added random variation to the longitude and latitude of each data point by adding a random number drawn from a normal (mean $=0$, standard deviation $=1$ ) distribution, which allowed testing for autocorrelation of the residuals even due to the equations obtained from the same locations. When autocorrelation was detected, we corrected it by adding an extra variable (lag1) obtained from the residuals of the model lagged one position as proposed by Bivand, Pebesma, and Gómez-Rubio (2013) (see Supporting Information Appendix S8).

2. In the second model, or Shape model, we additionally included the shape of the arthropods estimated by the three major geometric morphometric components (PCGMs).

3. In the third model, or Geographic model, we additionally included the geographic variables longitude, absolute latitude and altitude. We included them as independent variables because regardless of controlling for spatial autocorrelation we wanted to test the geographic effects per se, even beyond the correlation with climatic variables (see Supporting Information Table
S6). The idea behind this approach is that geographic variables can act as proxies of unknown environmental selective factors affecting the evolution of allometries. For instance, absolute latitude could be affecting allometric values because it can be a proxy of the strength, frequency and diversity of biotic interactions (Dobzhansky, 1950; Moya-Laraño, 2010; Schemske, 2009; Schemske, Mittelbach, Cornell, Sobel, \& Roy, 2009). Furthermore, if these variables explained a relevant amount of the variance in the model, their inclusion would increase the accuracy of the remaining estimates (e.g., NDVI)

4. In the fourth model, or Full model, we additionally added the two climatic variables MAT and MAP. Both temperature and water availability could directly affect growth beyond ecosystem productivity as well as productivity itself. To test whether the results concerning NDVI were robust across trophic levels or type of allometry, we also compared the Full models with models that included the interactions between type of allometry and NDVI and feeding habits (or their grouping by trophic level) and NDVI.

All analyses were performed with the function "Im" (R 3.4.1, R Development Core Team, 2016) and the main figures of partial effects produced by means of the R package "effects" (Fox, 2003). Models were compared via Akaike's information criterion (AIC; Burnham \& Anderson, 2002). To ensure normality of the residuals, we first transformed the $a$ and the $b$ values via optimality by the iterative use of the function "MLE_LambertW" within the R library "LambertW" (Georg, 2016), and then we additionally normalized the residuals of the models by the same procedure. Furthermore, both the dependent variable and all explanatory variables were standardized (mean $=0$, standard deviation $=1$ ) to make the magnitude of the effects among the different environmental variables comparable in terms of standard deviation units via standardized regression coefficients (Schroeder, Sjoquist, \& Stephan, 1986). Note that the use of standardized coefficients does not alter the amount of explained variance (coefficient of determination) or the associated $p$ values. Also, as sample size could have affected the accuracy in the estimates of the allometric parameters in each of the fitted equations, we ran all the analyses weighting by sample size, which allowed a $50 \%$ larger sample size than weighting by the SE of the estimates. As a sensitivity analysis, we ran the full models using robust regression in the function "rlm" of the R library "MASS".

\section{3 | RESULTS}

Comparisons of the Base, Shape, Geographic and Full models suggested that shape PCs, geographic and climatic variables should be included in the models explaining both the scaling (a) and the allometric $(b)$ factors (Table 1 ).

Both the scaling (a) and allometric (b) factors were strongly and negatively affected by the target variable NDVI in all the Base, Shape, Geographic and Full models (Figure 3a,b, Table 2, see Supporting Information Tables S7 and S8). Both the scaling (a) and allometric 
TAB LE 1 Summary of Akaike information criterion (AIC) and $R^{2}$ values of the models for both allometric factors. In the mass-length relationship $M=a L^{b}, M=$ mass $(\mathrm{mg})$ and $L=$ length $(\mathrm{mm})$

\begin{tabular}{llrl} 
Factor & Model & AIC & \multicolumn{1}{c}{$\boldsymbol{R}^{2}$} \\
\hline Scaling $a$ & Base model & 761 & .613 \\
& Shape model & 722 & .671 \\
& Geographic model & 672 & .730 \\
& Full model & 650 & .754 \\
\hline Allometric $b$ & Base model & 1,019 & .450 \\
& Shape model & 942 & .586 \\
& Geographic model & 905 & .644 \\
& Full model & 848 & .716 \\
\hline
\end{tabular}

(b) factors were negatively affected by the absolute latitude and altitude (Figure 3c-f, Table 2, see Supporting Information Tables S7 and S8). Regarding the climatic variables MAT and MAP, both the scaling factor $a$ and the allometric factor $b$ were negatively affected by MAT (Figure $3 \mathrm{~g}, \mathrm{~h}$ ) and only allometric factor $b$ was negatively affected by MAP (Figure 3i,j). For the scaling factor $a$, the variables ordered from strongest to weakest negative effects according to their standardized partial regression coefficients were absolute latitude, NDVI, altitude and MAT. Geometric morphometric variables had positive and relatively weaker effects with PCGM1, PCGM2 and PCGM3 showing effects from strongest to weakest (Table 2). Overall, the full model for a explained around $75 \%$ of the variance $\left(R^{2}=.75\right)$ (Table 1). For the allometric factor $b$, the variables ordered from strongest to weakest negative effects were absolute latitude, MAT, altitude, NDVI and MAP. PCGM1 and PCGM3 had stronger and weaker positive effects, respectively (Table 2 ). Overall, the full model for $b$ explained around $71 \%$ of the variance $\left(R^{2}=.71\right.$; Table 1$)$. The spatial autocorrelation of the residuals was successfully corrected in all models as shown in the correlograms (see Supporting Information Figures S10 and S11). The additional lagged term was no longer significant in the full models and barely significant for $a$ and not significant for $b$ in the geographic model. However, we left this variable in the final models for consistency. Taxonomic class was highly significant in both Full models (a: $F_{5,265}=31.37, p<.001$ and $b: F_{5,265}=18.72, p<.001$ ) and post-hoc tests revealed strong differences among some of the taxonomic classes (see Supporting Information Figure S12). The results of the robust linear regression for the Full models were qualitatively the same, with all significant terms matching those of the general linear model with normalized residuals. However, the relative effects detected for the predictors were two to three times weaker, likely because of the lack of normality in the residuals (see Supporting Information Table S9).

However, the type of allometry showed a strong significant interaction with NDVI for both the scale factor $a\left(F_{2,263}=8.61, p=\right.$ $.0002)$ and the allometric factor $b\left(F_{2,263}=5.04, p=.0071\right)$. The plot to check for the nature of the interaction shows a negative relationship between NDVI and allometric factors $a$ and $b$ for both evolutionary and ontogenetic allometries (see Supporting Information Figures S13a,b), with perhaps a less steep relationship for the allometric factor $b$ in ontogenetic allometry. Static allometries tend to have a positive relationship between NDVI and allometric factors $a$ and $b$. However, the sample size is too small and precludes us from reaching any firm conclusions. We had enough sample size to run the full model only for evolutionary allometries, and the results were qualitatively identical to those using the entire dataset (see Supporting Information Table S10). For the ontogenetic model we did not have enough sample size to run the full model, but with the shape model alone (with much fewer parameters), the negative relationship between both of the allometric factors and NDVI prevailed (see Supporting Information Table S11). Thus, our results were robust and consistent for evolutionary allometries, and likely for ontogenetic allometries.

After removing 28 data points for which it was not possible to assign the feeding habits (undefined, see Supporting Information Figure S7) of the arthropods involved, we found no interaction between feeding habits and NDVI for the scaling factor $a\left(F_{3,233}=0.78\right.$, $p=.5040$ ) but did find a significant interaction for allometric factor $b\left(F_{3,233}=5.15, p=.0018\right)$ (see Supporting Information Figure S14). When grouping the feeding habits by trophic level (high: predators and omnivores and low: decomposers and herbivores;) we found a strong significant interaction, which showed how the relationship between allometric factor $b$ and NDVI was substantially steeper for lower trophic levels $\left(F_{1,237}=15.85, p<.001\right.$; Figure 4).

\section{4 | DISCUSSION}

Our results are consistent with the notion that a developmental mechanism can explain the evolution of allometry (Shingleton et al., 2007). Assuming that nutrition can differently shape the reaction norms of body length and mass, this leads to nutrition-dependent static allometries that set the raw material for natural selection. If the above mechanism is plausible, we predicted that globally NDVI should have an effect on both the scaling (a) and allometric (b) factors. After controlling for potentially confounding factors, we indeed found a negative, strong and significant relationship between NDVI and both $a$ and $b$. Interpretation of the results is made easier if we assume that lower values for the allometric factors are a sign of faster development involving lower energy storage. Thus, the negative relationship between productivity and the allometric factors can be explained because in ecosystems with higher productivity animals would develop faster without acquiring more mass for storage or building other body structures. The ultimate cause could be differences in selection for energy storage across ecosystems differing in productivity. Understanding how the energy available in ecosystems translates into mass-length allometric relationships is equivalent to understanding how food acquisition is stored in the form of body condition. Indeed, a recent body condition index, the scaled mass index (SMI; Peig \& Green, 2009) takes into account the allometric factor of the mass-length relationship, with animals coming from populations with higher allometric factors having relatively better body conditions as they grow in body size. Therefore, 


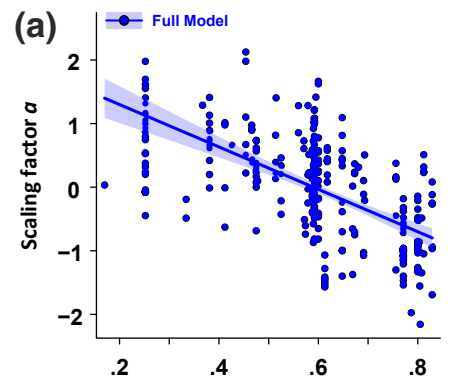

Normalized Difference Vegetation Index (NDVI)
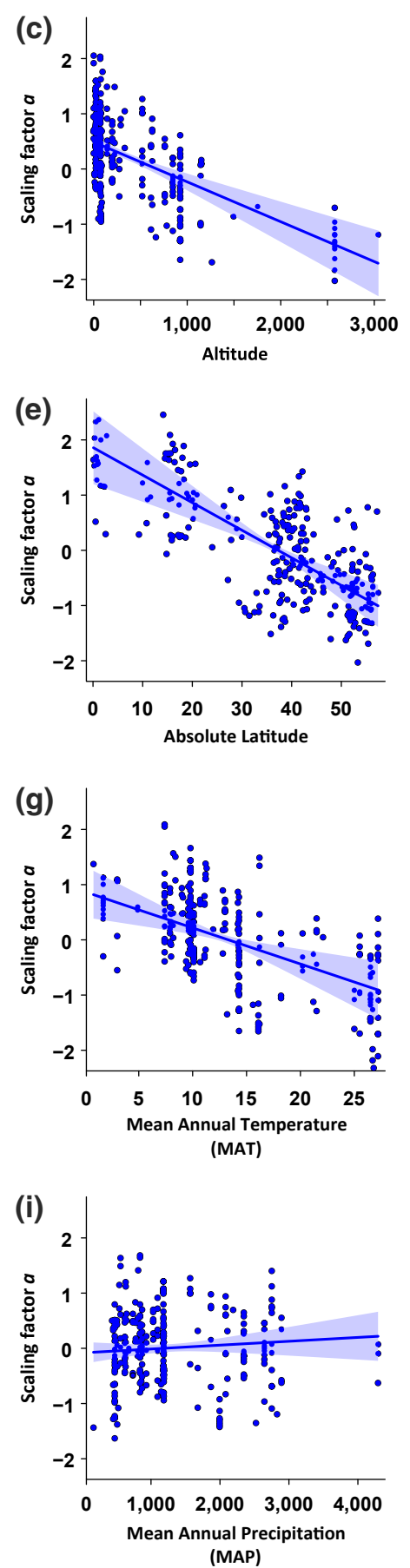

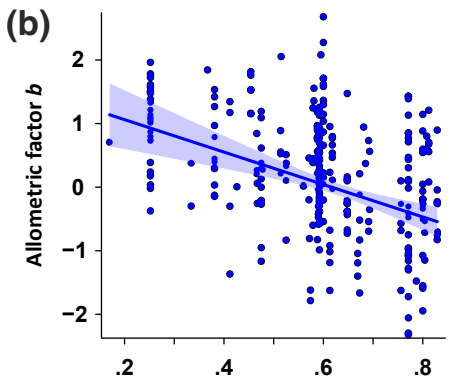

Normalized Difference Vegetation Index (NDVI)
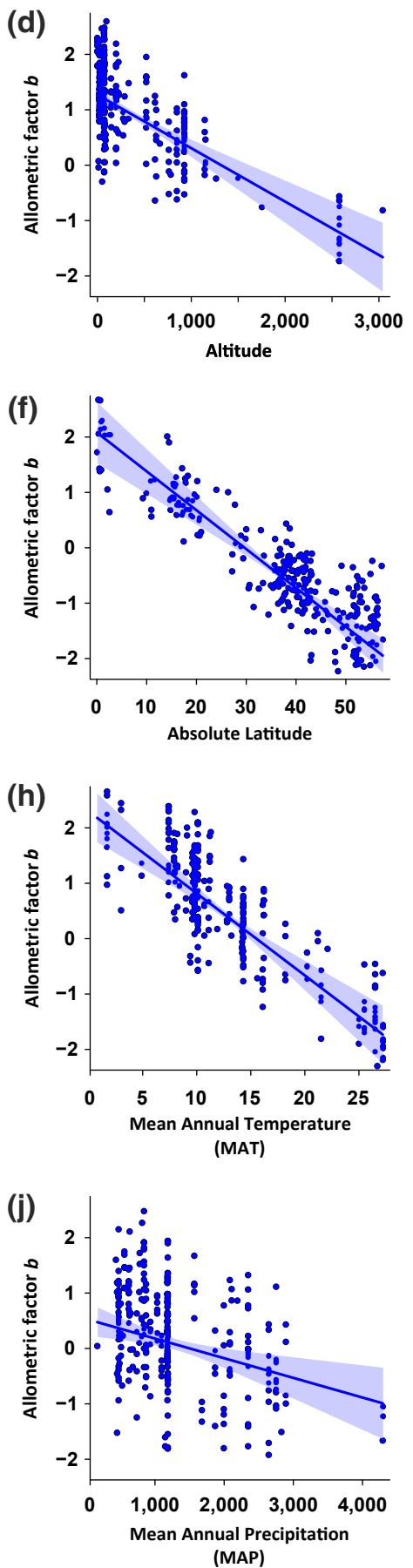

FIGURE 3 Relationship between the allometric factors ( $a$ and $b$ ) and the normalized difference vegetation index (NDVI), geographic and climatic variables according to the Full model. We show partial effects on the scaling factor $a$ of (a) NDVI, (c) altitude, (e) absolute latitude, (g) mean annual temperature (MAT) and (i) mean annual precipitation (MAP), and on the allometric factor $b$ of (b) NDVI, (d) altitude, (f) absolute latitude, (h) MAT and (j) MAP. Blue areas represent $95 \%$ confidence bands. Units are missing on the axes because the variables are standardized. However, the original variables were measured in: altitude $(m)$, absolute latitude and longitude $\left({ }^{\circ}\right.$ degrees in decimal notation), MAT $\left({ }^{\circ} \mathrm{C}\right)$ and MAP ( $\mathrm{mm} /$ year). NDVI is a proportion of a difference that ranges between -1 and +1 . In the mass-length relationship $M=a L^{b}, M$ $=$ mass $(\mathrm{mg})$ and $L=$ length $(\mathrm{mm})$ [Colour figure can be viewed at wileyonlinelibrary. com] 
TABLE 2 Summary of the results of the Full model analysing the predictors on the scaling factor $a$ and allometric factor b. Units are missing in the table because the variables are standardized. However, the original variables were measured in: altitude $(\mathrm{m})$, absolute latitude and longitude ( ${ }^{\circ}$ degrees in decimal notation), mean annual temperature (MAT; $\left.{ }^{\circ} \mathrm{C}\right)$ and mean annual precipitation (MAP; $\mathrm{mm}$ / year). Normalized difference vegetation index (NDVI) is a proportion of a difference that ranges between -1 and +1 . In the mass-length relationship $M=a L^{b}, M$ $=$ mass $(\mathrm{mg})$ and $L=$ length $(\mathrm{mm})$

\begin{tabular}{|c|c|c|c|c|c|c|}
\hline Factor & Variables included & Estimate & $S E$ & $F$ & $d f$ & $p(F)$ \\
\hline \multirow[t]{13}{*}{ Scaling $a$} & (intercept) & 0.5347 & 0.0785 & & & \\
\hline & $b$ & -0.4048 & 0.0362 & 125.021 & 1,265 & $<.001$ \\
\hline & Class & & & 31.369 & 5,265 & $<.001$ \\
\hline & PCGM1 & 0.2714 & 0.0736 & 13.592 & 1,265 & $<.001$ \\
\hline & PCGM2 & 0.1054 & 0.0398 & 6.993 & 1,265 & .0087 \\
\hline & PCGM3 & 0.0988 & 0.0466 & 4.491 & 1,265 & .0350 \\
\hline & Altitude & -0.4711 & 0.0734 & 41.189 & 1,265 & $<.001$ \\
\hline & Absolute latitude & -0.7813 & 0.1428 & 29.944 & 1,265 & $<.001$ \\
\hline & Longitude & 0.0587 & 0.0456 & 1.654 & 1,265 & .1996 \\
\hline & MAT & -0.4480 & 0.1246 & 12.920 & 1,265 & $<.001$ \\
\hline & MAP & 0.0547 & 0.0579 & 0.892 & 1,265 & .3458 \\
\hline & NDVI & -0.5408 & 0.0548 & 97.321 & 1,265 & $<.001$ \\
\hline & lag1 & 0.0418 & 0.0572 & 0.535 & 1,265 & .4653 \\
\hline \multirow[t]{13}{*}{ Allometric $b$} & (intercept) & 0.1987 & 0.1173 & & & \\
\hline & $a$ & -0.7401 & 0.0710 & 108.607 & 1,265 & $<.001$ \\
\hline & Class & & & 18.723 & 5,265 & $<.001$ \\
\hline & PCGM1 & 0.3649 & 0.1046 & 12.175 & 1,265 & $<.001$ \\
\hline & PCGM2 & 0.0650 & 0.0574 & 1.281 & 1,265 & .2587 \\
\hline & PCGM3 & 0.2763 & 0.0650 & 18.082 & 1,265 & $<.001$ \\
\hline & Altitude & -0.7943 & 0.0982 & 65.380 & 1,265 & $<.001$ \\
\hline & Absolute latitude & -1.7736 & 0.1891 & 87.959 & 1,265 & $<.001$ \\
\hline & Longitude & 0.2231 & 0.0640 & 12.167 & 1,265 & $<.001$ \\
\hline & MAT & -1.3434 & 0.1664 & 65.209 & 1,265 & $<.001$ \\
\hline & MAP & -0.2622 & 0.0803 & 10.658 & 1,265 & .0012 \\
\hline & NDVI & -0.3911 & 0.0829 & 22.277 & 1,265 & $<.001$ \\
\hline & lag1 & 0.0794 & 0.0464 & 2.926 & 1,265 & .0883 \\
\hline
\end{tabular}

Note: $p$ values: italic-bold < .001, bold .001-.01, italic .01-.05 and normal > .05. PCGMs are principal components which explained the variance in shape or body bauplan. lag 1 is the correlation between residuals of the model and the residuals of the model lagged one position. our results imply that animal populations in ecosystems with higher amounts of energy available grow with poorer body conditions. This could arise from weaker selection for energy storage in relatively rich environments, where shorter developmental times and faster growth in length would be favoured by natural selection instead. This also provides us with an adaptive mechanism to explain why and how mass and length reaction norms would differ (Shingleton et al., 2007), closing the eco-evo-devo loop defined by the ecological evolutionary developmental biology. Although, as pointed out in the Introduction, in principle we could not rule out the possibility that phenotypic plasticity is behind this mechanism. The response to energy could still occur at the ecological time-scale, however this certainly would not be the case for evolutionary allometries, which encompass the major part of our dataset.

Indeed, our database did not include enough sample size to test the hypothesis for all types of allometries. However, as the results for evolutionary allometries were consistent with the entire model, and with a simpler model we also uncovered a negative association between NDVI and allometry for ontogenetic allometries, we can conclude that at least for two types of allometries the pattern holds. One possible interpretation of this result is that during diversification there has been selection upon the reaction norms of both ontogenetic and static allometries, resulting in the pattern found for evolutionary allometries, which would have originated from selection responses of the reaction norms. Thus, overall, our results are consistent with the hypothesis that a developmental mechanism can explain the evolution of allometries (Shingleton et al., 2007).

Remarkably, we found that for the allometric factor $b$, the effect was stronger for lower trophic levels, which suggests that energy storage is more important in higher trophic levels regardless of primary productivity. This is consistent with the fact that soil predators, such as spiders, are food limited (Wise, 1993) and have developed structures for energy storage to overcome periods of food limitation (Foelix, 1996; Grassé, 1949), and even decrease their metabolic rates during periods of starvation (Anderson, 1970). We found a significant interaction between the type of allometry and both the 


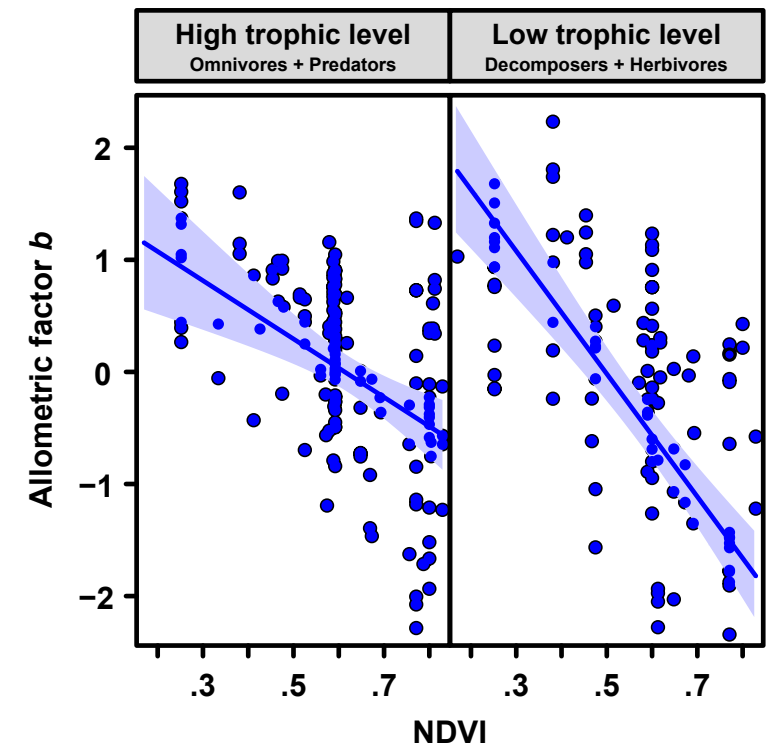

(Normalized Difference Vegetation Index)

FIGURE 4 Interaction between trophic level and normalized difference vegetation index (NDVI) for the allometric factor $b$, according to the Full model. Blue areas represent $95 \%$ confidence bands. NDVI is a proportion of a difference that ranges between -1 and +1 . In the mass-length relationship $M=a L^{b}, M=$ mass $(\mathrm{mg})$ and $L=$ length $(\mathrm{mm})$ [Colour figure can be viewed at wileyonlinelibrary. com]

scaling and allometric factors. However, the similar visual pattern of the relationships for each type of allometry (see Supporting Information Figure S13), the relatively small sample sizes for ontogenetic and static allometries, and the consistent pattern of the results between evolutionary allometries and the general pattern with the entire dataset, preclude us from making any firm conclusions about whether different selective pressures differently affect each type of allometry.

As for the shape (bauplan) of the animals we found that principal components of shape analysis (PCGMs) have an influence on both the scaling and allometric factors. PCGM2 (body thickness) and PCGM3 (relative abdomen volume) positively affect the scaling factor $a$, probably indicating that animals with higher capacity to store nutrients according to their shape do actually have larger storages and slower development. PCGM1 (slenderness with reduction of cephalic area) reflects animals with very elongated bodies and relatively small cephalic parts, such as myriapodes. This axis has a positive effect on both the scaling factor $a$ and allometric factor $b$, probably indicating that for animals with very elongated bodies, growing in length entails a relatively higher investment in high density structures, such as muscle to move all the legs (Grassé, 1949). Finally, the fact that PCGM3 (relative abdomen volume) is positively associated with the allometric factor $b$ may reflect again that a shape allowing a relatively larger storage capacity results in larger real storages. Similarly, the fact that Arachnida have both higher scaling and higher allometric factors relative to all other taxa (see Supporting Information Figure S12) may be due to their higher storage capacities from their expandable abdomens and storing caeca in their guts (Grassé, 1949).
We also found that geographic and climatic variables contribute substantially to the variability of the scaling and allometric factors. Geographic variables can be considered as surrogates of some unknown environmental variables (Legendre, 1993) that could act as selective factors on the evolution of allometries. As the main climatic and productivity variables that covary with altitude and latitude were accounted for in the analysis (i.e., MAT, MAP and NDVI), any geographic pattern should reflect selective pressures other than average climate. Because of the short duration of the growing season, arthropods inhabiting high altitudes and latitudes usually grow faster (Dmitriew, 2011; Laiolo \& Obeso, 2017; Yamahira \& Conover, 2002). Thus, the negative association between both of the allometric coefficients and altitude and absolute latitude could be a consequence of selection favouring faster development or growth in length. In addition, at high altitudes oxygen pressure $\left(\mathrm{PO}_{2}\right)$ is much lower (Greenlee \& Harrison, 2004; Hoback \& Stanley, 2001; Laiolo \& Obeso, 2017), resulting in chronic exposure to relatively hypoxic environments, which affects several life history traits (Woods \& Hill, 2004). Hence, the negative relationship between altitude and both the scaling and allometric factors may be due to a decrease in body density caused by the increased empty spaces of an improved respiratory system (e.g., increase in number of tracheas), which may contribute to compensating for the lack of oxygen (Dillon, Frazier, \& Dudley, 2005). Lastly, altitudinal and latitudinal variation in the number, strength and diversity of biotic interactions (Dobzhansky, 1950; Laiolo \& Obeso, 2017; Moya-Laraño, 2010; Pianka, 1966; Roslin et al., 2017) could potentially explain the negative relationship that we found if biotic interactions would select for energy storage. On the one hand, one may think that this is unlikely because at least from competition and predation, usually faster growth (shorter developmental time) is favoured (Dmitriew, 2011), which would have led to the opposite pattern than the one we found. On the other hand, higher predation rates may select for slower growth (extended developmental time) because this will decrease predation risk (Lima \& Dill, 1990; reviewed in Dmitriew, 2011). Therefore, we cannot dismiss the possibility that biotic interactions are behind the negative relationships between absolute latitude and latitude and the allometric factors.

Among the climate variables, temperature (MAT) affects negatively both allometric coefficients. Higher temperatures involve higher metabolic rates (Brown, Gillooly, Allen, Savage, \& West, 2004), and in general faster paces of life with shorter developmental times, which could explain the negative relationship found, provided that by using multiple regression this is an effect that has been evaluated orthogonally to altitude and absolute latitude. Another potential explanation is that animals in very hot environments can prevent overheating by having longer bodies relative to their mass [higher surface/volume (S/V) ratios], which could allow excessive heat to dissipate through the cuticle. This explanation assumes that mass is proportional to body volume and thus to Length ${ }^{3}$ (Gibbings, 2011), and that volume can still evolve beyond the constraint imposed by the bauplan. Indeed, we found the negative pattern once controlled for the geometric morphometrics PCGMs. Similarly, in colder 
environments heat will be retained more efficiently with lower S/V ratios, allowing animals to expand their daily activities.

Although precipitation may absorb in part the proportion of variance of the available energy (i.e., more rain entails higher productivity), the negative pattern between MAP and the allometric factor $b$ could also be indicative of a relaxation in selection for building up structures for desiccation resistance. Arthropods have a variety of cuticle structures to protect themselves from the loss of water by transpiration, such as epicuticle lipids (Hadley, 1982). Increasing the thickness of the integumental cuticle is also a frequent defence against water loss (Vittori \& Štruss, 2014). Assuming that these structures add extra weight to the animals, when water availability is high, selection would favour growing (faster) in length instead of investing in these structures. We used our own extended dataset on mass-length relationships to compare the mass-length ratios of adults versus last-instar larvae in beetles measuring between 1 and $10 \mathrm{~mm}$ and found that the ratio of body masses between the non-sclerotized larvae and the adults of the same length is $2.5-4.5$, indicating that at least for beetles, building a water-resistant cuticle can be extremely costly.

In addition to the evolutionary implications of our findings, the ecological consequences may also be important. Lower energy storage in the more productive ecosystems, and the suggested faster development in warmer and wetter environments, as well as at higher altitudes and latitudes, may be a sign that energy is processed differently by the soil fauna in different parts of the globe, and in locations of contrasting climates. The latter could affect studies in which it is assumed that mass-length relationships for the different animal groups are invariant, and that estimates coming from different localities and climates can be used indistinctly (e.g., Ehnes et al., 2014; Melguizo-Ruiz, Jiménez-Navarro, \& Moya-Laraño, 2016). In addition, these findings may have important consequences for the energy equivalence rule (Damuth, 1981), which states that animal populations in communities use an equal amount of energy regardless of the individual body sizes (in terms of mass), which explains why larger animals have lower abundances and smaller animals have higher abundances. Our evidence that energy is processed differently in different parts of the globe and in different climates may explain why this rule is far from universal (Ehnes et al., 2014; Sewall, Freestone, Hawes, \& Andriamanarina, 2013).

One drawback of our study is that we could not fit a phylogeny to control for common ancestry as is usually done in the evolutionary comparative method (Harvey \& Pagel, 1991). We instead fitted class, the lowest taxonomic level that we could confidently obtain from all studies. The fact that class was highly significant for both the scaling and allometric factors strongly suggests that there is a phylogenetic signal for these factors and that an accurate phylogeny fitted to our linear models could provide a slightly different picture than the one we obtained. Unfortunately, the highly heterogeneous nature of the database, especially in terms of the level of accuracy in taxonomic information, along with the difficulties in obtaining enough molecular information for all the taxa cited, precluded us from building such a phylogeny.
Overall, this study provides strong evidence that allometries can evolve. Previous studies on the evolution of allometries within populations have shown that the allometric factor $b$ has a much lower evolutionary potential than the scaling factor a (Egset et al., 2012; Frankino et al., 2005; Maynard-Smith et al., 1985; Pélabon et al., 2014). Our results show that despite this lack of microevolutionary potential in the allometric factor $b$, it can evolve at the macroevolutionary level. One striking pattern that arises is the consistency of the predictors, which match very closely in significance and the direction of effects for both $a$ and $b$ factors, strongly suggesting that both allometric factors are subject to the same selective pressures.

\section{ACKNOWLEDGMENTS}

We thank E. de Mas for pointing out the idea that energy storage must evolve only in poor environments; N. Melguizo-Ruiz, J. M. Herrera, E. de Mas, J. Pato and G. Jiménez helped with field sampling; and J. Fox for his contributions about the doubts of the library "effects" for the R environment. This work was funded by grants CGL2014-61314-EXP and CGL2015-66192-R from the Spanish Ministerio de Economía y Competitividad (European funds FEDER) and P12-RNM-1521 from Junta de Andalucía (Fondo Europeo de Desarrollo Regional - FEDER). D. Ruiz-Lupión is enjoying a Formación de Profesorado Universitario (FPU13/04933) scholarship from the Spanish Ministerio de Educacion, Cultura y Deporte.

\section{DATA AVAILABILITY STATEMENT}

We confirm that, should the manuscript be accepted, the data supporting the results will be archived in Ruiz-Lupión, Dolores; Gómez, José María; Moya-Laraño, Jordi "Mass-length allometry database" 2018. DIGITAL.CSIC http://hdl.handle.net/10261/170286.

\section{ORCID}

Dolores Ruiz-Lupión (iD https://orcid.org/0000-0002-1309-315X José María Gómez iD https://orcid.org/0000-0001-6153-707X

Jordi Moya-Laraño (iD https://orcid.org/0000-0001-7141-3206

\section{REFERENCES}

Anderson, J. F. (1970). Metabolic rates of spiders. Comparative Biochemistry and Physiology, 33, 51-72. https://doi.org/10.1016/ 0010-406X(70)90483-4

Bivand, R. S., Pebesma, E. J., \& Gómez-Rubio, V. (2013). Applied spatial data analysis with R. New York, NY: Springer.

Bolstad, G. H., Cassara, J. A., Márquez, E., Hansen, T. F., van der Linde, K., Houle, D., \& Pélabon, C. (2015). Complex constraints on allometry revealed by artificial selection on the wing of Drosophila melanogaster. Proceedings of the National Academy of Sciences USA, 112(43), 13284-13289.

Brown, J. H., Gillooly, F., Allen, A. P., Savage, V. M., \& West, G. B. (2004). Toward a metabolic theory of ecology. Ecology, 85(7), 1771-1789. https://doi.org/10.1890/03-9000 
Burnham, K. P., \& Anderson, D. R. (2002). Model selection and multimodel inference: A practical information- theoretical approach. New York, NY: Springer-Verlag.

Capellesso, E. S., Scrovonski, K. L., Zanin, E. M., Hepp, L. U., Bayer, C., \& Sausen, T. L. (2016). Effects of forest structure on litter production, soil chemical composition and litter-soil interactions. Acta Botanica Brasilica, 30(3), 329-335. https://doi.org/10.1590/0102-33062016ab b0048

Clutton-Brock, T. H., \& Harvey, P. H. (1977). Primate ecology and social organization. Journal of Zoology, 18, 1-39. https://doi. org/10.1111/j.1469-7998.1977.tb04171.x

Cock, A. G. (1966). Genetical aspects of metrical growth and form in animals. Quarterly Review of Biology, 41, 131-190. https://doi. org/10.1086/404940

Damuth, J. (1981). Population density and body size in mammals. Nature, 290, 699-700. https://doi.org/10.1038/290699a0

Dillon, M. E., Frazier, M. R., \& Dudley, R. (2005). Into thin air: Physiology and evolution of alpine insects. Integrative and Comparative Biology, 46(1), 139-149.

Dmitriew, C. M. (2011). The evolution of growth trajectories: What limits growth rate? Biological Reviews, 86, 97-116. https://doi. org/10.1111/j.1469-185X.2010.00136.x

Dobzhansky, T. (1950). Evolution in tropics. American Scientist, 38, 209-221.

Egset, C. K., Hansen, T. F., Le Rouzic, A., Bolstad, G. H., Rosenqvist, G., \& Pélabon, C. (2012). Artificial selection on allometry: Change in elevation but not slope. Journal of Evolutionary Biology, 25, 938-948. https ://doi.org/10.1111/j.1420-9101.2012.02487.x

Ehnes, R. B., Rall, B. C., \& Brose, U. (2011). Phylogenetic grouping, curvature and metabolic scaling in terrestrial invertebrates. Ecology Letters, 14, 993-1000. https://doi.org/10.1111/j.1461-0248.2011.01660.x

Ehnes, R. B., Pollierer, M. M., Erdmann, G., Klarner, B., Eitzinger, B., Digel, C., ... Brose, U. (2014). Lack of energetic equivalence in forest soil invertebrates. Ecology, 95(2), 527-537. https://doi. org/10.1890/13-0620.1

Emlen, D. J., Warren, I. A., Johns, A., Dworkin, I., \& Lavine, L. C. (2012). A mechanism of extreme growth and reliable signaling in sexually selected ornaments and weapons. Science, 337, 860-864. https://doi. org/10.1126/science.1224286

Fagan, W. F., \& Denno, R. F. (2004). Stoichiometry of actual vs. potential predator-prey interactions: Insights into nitrogen limitation for arthropod predators. Ecology Letters, 7, 876-883. https://doi. org/10.1111/j.1461-0248.2004.00641.x

Fagan, W. F., Siemann, E., Mitter, C., Denno, R. F., Huberty, A. F., Woods, H. A., \& Elser, J. J. (2002). Nitrogen in insects: Implications for trophic complexity and species diversification. The American Naturalist, 160, 784-802. https://doi.org/10.1086/343879

Farr, T. G., Rosen, P. A., Caro, E., Crippen, R., Duren, R., Hensley, S., ... Alsdorf, D. (2007). The shuttle radar topography mission. Reviews of Geophysics, 45(2). https:/doi.org/10.1029/2005RG000183

Ficetola, G. F., Scali, S., Denoël, M., Montinaro, G., Vukov, T. D., Zuffi, M. A. L., \& Padoa-Schioppa, E. (2010). Ecogeographical variation of body size in the newt Triturus carnifex: Comparing the hypotheses using an information-theoretic approach. Global Ecology and Biogeography, 19(4), 485-495.

Foelix, R. F. (1996). Biology of spiders. New York, NY: Oxford University Press.

Fox, J. (2003). Effect displays in R for generalized linear models. Journal of Statistical Software, 8(15), 1-27.

Frankino, W. A., Zwaan, B. J., Stern, D. L., \& Brakefield, P. M. (2005). Natural selection and developmental constraints in the evolution of allometries. Science, 307(5710), 718-720.

Georg, G. M. (2016). LambertW: An R package for Lambert W x F random variables. $\mathrm{R}$ package version 0.6.4. Retrieved from https://cran.rproject.org/web/packages/LambertW/LambertW.pdf

Gibbings, J. C. (2011). Dimensional analysis. London: Springer-Verlag.
Gould, S. J. (1966). Allometry and size in ontogeny and phylogeny. Biological Reviews, 41, 587-638. https://doi.org/10.1111/j.1469185X.1966.tb01624.x

Gould, S. J. (1977). Ontogeny and phylogeny. Cambridge, MA: Belknap Press of Harvard University Press.

Grassé, P. P. (1949). Tome VI, Onychophores, Tardigrades, Arthropodes (généralités), Trilobitomorphes, Chélicérates. Traité de zoologie (Anatomie, Sytématigque, Biologie). Masson et Cie éditeurs, 120 boulevard Saint-Germain Paris.

Greenlee, K. J., \& Harrison, J. F. (2004). Development of respiratory function in the American locust Schistocerca americana I. Across-instar effects. Journal of Experimental Biology, 207, 497-508.

Hadfield, J. D., \& Nakagawa, S. (2010). General quantitative genetic methods for comparative biology: Phylogenies, taxonomies and multi-trait models for continuous and categorical characters. Journal of Evolutionary Biology, 23, 494-508. https://doi. org/10.1111/j.1420-9101.2009.01915.x

Hadley, N. F. (1982). Cuticle ultrastructure with respect to the lipid waterproofing barrier. Journal of Experimental Zoology, 222, 239-248. https://doi.org/10.1002/jez.1402220306

Hansen, T. F., \& Bartoszek, K. (2012). Interpreting the evolutionary regression: The interplay between observational and biological errors in phylogenetic comparative studies. Systematic Biology, 61, 413-425. https://doi.org/10.1093/sysbio/syr122

Harvey, P. H., \& Pagel, M. D. (1991). The comparative method in evolutionary biology. Oxford Series in Ecology and Evolution. UK: Oxford University Press.

Hijmans, R. J., Cameron, S. E., Parra, J. L., Jones, P. G., \& Jarvis, A. (2005). Very high resolution interpolated climate surfaces for global land areas. International Journal of Climatology, 25, 1965-1978. https:// doi.org/10.1002/joc.1276

Hoback, W. W., \& Stanley, D. W. (2001). Insects in hypoxia. Journal of Insect Physiology, 47, 533-542. https://doi.org/10.1016/S0022-1910 (00)00153-0

Hutchinson, M. F. (2004). ANUSPLIN version 4.3. centre for resource and environmental studies. Canberra, Australia: The Australian National University.

Huxley, J. S. (1932). Problems of relative growth. Baltimore, MD: Johns Hopkins University Press.

Jakob, E. M., Marshall, S. D., \& Uetz, G. W. (1966). Estimating fitness: A comparison of body condition indices. Oikos, 77(1), 61-67.

Klingenberg, C. P. (1998). Heterochrony and allometry: The analysis of evolutionary change in ontogeny. Biological Reviews, 73(1), 79-123. https://doi.org/10.1017/S000632319800512X

LaBarbera, M. (1989). Analyzing body size as a factor in ecology and evolution. Annual Review of Ecology and Systematics, 20, 97-117. https:// doi.org/10.1146/annurev.es.20.110189.000525

Laiolo, P., \& Obeso, J. R. (2017). Chapter 11. Life-history responses to the altitudinal gradient. High mountain conservation in a changing world. Advances in Global Change Research, 62, 253-283.

Lande, R. (1979). Quantitative genetic analysis of multivariate evolution, applied to brain: Body size allometry. Evolution, 33(1), 402-416. https ://doi.org/10.2307/2407630

Legendre, P. (1993). Spatial autocorrelation: Trouble or new paradigm?. Ecology, 74(6), 1659-1673. https://doi.org/10.2307/1939924

Lima, S. L., \& Dill, L. M. (1990). Behavioral decisions made under the risk of predation: A review and prospectus. Canadian Journal of Zoology, 68, 619-640. https://doi.org/10.1139/z90-092

Maynard-Smith, J., Burian, R., Kauffman, S., Alberch, P., Campbell, J., Goodwin, B., ... Wolpert, L. (1985). Developmental constraints and evolution: A perspective from the Mountain Lake conference on development and evolution. Quarterly Review of Biology, 60(3), 265287.

Melguizo-Ruiz, N., Jiménez-Navarro, G., \& Moya-Laraño, J. (2016). Beech cupules as keystone structures for soil fauna. PeerJ, 4, e2562. https:// doi.org/10.7717/peerj. 2562 
Moya-Laraño, J. (2010). Can temperature and water availability contribute to the maintenance of latitudinal diversity by increasing the rate of biotic interactions? Open Ecology Journal, 3, 1-13. https://doi. org/10.2174/1874213001003010001

Moya-Laraño, J., Macías-Ordóñez, R., Blanckenhorn, W. U., \& FernándezMontraveta, C. (2008). Analyzing body condition: Mass, volume or density? Journal of Animal Ecology, 77, 1099-1108.

Olalla-Tárraga, M. Á., \& Rodríguez, M. Á. (2007). Energy and interspecific body size patterns of amphibian faunas in Europe and North America: Anurans follow Bergmann's rule, urodeles its converse. Global Ecology and Biogeography, 16(5), 606-617. https://doi. org/10.1111/j.1466-8238.2007.00309.x

Outomuro, D., \& Johansson, F. A. (2017). A potential pitfall in studies of biological shape: Does size matter? Journal of Animal Ecology, 86(6), 1447-1457. https://doi.org/10.1111/1365-2656.12732

Owen, R. E., \& Harder, L. D. (1995). Heritable allometric variation in bumble bees: Opportunities for colony-level selection of foraging ability. Journal of Evolutionary Biology, 8, 725-738. https://doi.org/10.104 6/j.1420-9101.1995.8060725.x

Peig, J., \& Green, A. (2009). New perspectives for estimating body condition from mass/length data: The scaled mass index as an alternative method. Oikos, 118, 1883-1891. https://doi. org/10.1111/j.1600-0706.2009.17643.x

Pélabon, C., Firmat, C., Bolstad, G. H., Voje, K. L., Houle, D., Cassara, J., .. Hansen, T. F. (2014). Evolution of morphological allometry. Annals of the New York Academy of Sciences, 1320, 58-75.

Pianka, E. R. (1966). Latitudinal gradients in species diversity: A review of concepts. The American Naturalist, 100, 33-46. https://doi. org/10.1086/282398

Raubenheimer, D., Simpson, S. J., \& Mayntz, D. (2009). Nutrition, ecology and nutritional ecology: Toward an integrated framework. Functional Ecology,23,4-16.https://doi.org/10.1111/j.1365-2435.2009.01522.x

R Core Team. (2016). R: A language and environment for statistical computing. Vienna, Austria: R Foundation for Statistical Computing. Retrieved from http://www.R-project.org/

Reiss, M. J. (1989). The allometry of growth and reproduction. UK Cambridge University Press.

Roslin, T., Hardwick, B., Novotny, V., Petry, W. K., Andrew, N. R., Asmus, A., ... Slade, E. M. (2017). Higher predation risk for insect prey at low latitudes and elevations. Science, 356, 742-744. https://doi. org/10.1126/science.aaj1631

Schemske, D. W. (2009). Chapter 12. Biotic interactions and speciation in the tropics. In R. Butlin, J. Bridle, \& D. Schluter (Eds.), Speciation and patterns of diversity (pp. 219-239). UK: Cambridge University Press.

Schemske, D. W., Mittelbach, G. G., Cornell, H. V., Sobel, J. M., \& Roy, K. (2009). Is there a latitudinal gradient in the importance of biotic interactions? Annual Review of Ecology, Evolution, and Systematics, 40, 245-269. https://doi.org/10.1146/annurev.ecols ys.39.110707.173430

Schroeder, L. D., Sjoquist, D. L., \& Stephan, P. A. (1986). Understanding regression analysis: An introductory guide. Thousand Oaks, CA: Sage.

Sewall, B. J., Freestone, A. L., Hawes, J. E., \& Andriamanarina, E. (2013). Sizeenergy relationships in ecological communities. PloS one, 8(8), e68657. https://doi.org/10.1371/journal.pone.0068657

Shingleton, A. W., Frankino, W. A., Flatt, T., Nijhout, H. F., \& Emlen, D. J. (2007). Size and shape: The developmental regulation of static allometry in insects. BioEssays, 29, 536-548. https://doi.org/10.1002/ bies. 20584

Stillwell, R. C., Shingleton, A. W., Dworkin, I., \& Frankino, W. A. (2016). Tipping the scales: Evolution of the allometric slope independent of average trait size. Evolution, 70(2),433-444. https://doi.org/10.1111/ evo.12865

Tobler, A., \& Nijhout, H. F. (2010). Developmental constraints on the evolution of wing-body allometry in Manduca sexta. Evolution and Development, 12, 592-600. https://doi.org/10.1111/j.1525-142X.2010.00444.x

Valenzuela-Sánchez, A., Cunningham, A. A., \& Soto-Azat, C. (2015). Geographic body size variation in ectotherms: Effects of seasonality on an anuran from the southern temperate forest. Frontiers in Zoology, 12(1), 37. https://doi.org/10.1186/s12983-015-0132-y

Verdin, J., Pedreros, D., \& Eilerts, G. (2003). Índice Diferencial de Vegetación Normalizado (NDVI). FEWS- Red de Alerta Temprana Contra la Inseguridad Alimentaria Centroamérica, USGS/EROS Data Center.

Vittori, M., \& Štruss, J. (2014). The integument in troglobitic and epigean woodlice (Isopoda: Oniscidea): A comparative ultrastructural study. Zoomorphology, 133(4), 391-401. https://doi.org/10.1007/ s00435-014-0232-9

Voje, K. L., \& Hansen, T. F. (2012). Evolution of static allometries: Adaptative change in allometric slopes of eye span in stalk-eyed flies. Evolution, 67(2), 453-467.

Voje, K. L., Hansen, T. F., Egset, C. K., Bolstad, G. H., \& Pélabon, C. (2014). Allometric constraints and the evolution of allometry. Evolution, 68(3), 866-885. https://doi.org/10.1111/evo.12312

Weier, J., \& Herring, D. (2000). Measuring vegetation (NDVI \& EVI). NASA Earth Observatory. Retrieved from https://earthobservatory.nasa. gov/Features/MeasuringVegetation/

White, J. F., \& Gould, S. J. (1965). Interpretation of allometric equations. The American Naturalist, 99(904), 5-18.

Wise, H. (1993). Reviewed work: Spiders in ecological webs. Journal of Arachnology, 23(1), 48-50.

Woods, H. A., \& Hill, R. I. (2004). Temperature-dependent oxygen limitation in insect eggs. Journal of Experimental Biology, 207, 2267-2276. https://doi.org/10.1242/jeb.00991

Yamahira, K., \& Conover, D. O. (2002). Intra- vs. interspecific latitudinal variation in growth: Adaptation to temperature or seasonality? Ecology, 83(5), 1252-1262.

Zelditch, M. L., Swiderski, D. L., \& Sheets, H. D. (2012). Geometric morphometrics for biologists. A primer. New York, NY: Elsevier Academic Press.

Zuur, A. F., leno, A. E. N., Walker, N., Savaliev, A. A., \& Smith, G. M. (2009). Mixed effects models and extensions in ecology with R. New York, NY: Springer-Verlag.

\section{BIOSKETCHES}

Dolores Ruiz-Lupión is interested in the modelling and ecology of both terrestrial and aquatic food webs, focusing on the populational, ecological and evolutionary consequences of predatorprey interactions under multiple environmental conditions.

José María Gómez is mostly interested in investigating the ecological and evolutionary consequences of interspecific interactions, focusing mostly but not exclusively on the interactions between plants and animals, and studying their genetic, populational, community, phenotypic and coevolutionary consequences.

Jordi Moya-Laraño is an evolutionary ecologist with an interest in biotic interactions, especially food webs, and their role in the integration of ecology and evolution at different temporal and spatial scales.

\section{SUPPORTING INFORMATION}

Additional supporting information may be found online in the Supporting Information section at the end of the article.

How to cite this article: Ruiz-Lupión D, Gómez JM, MoyaLaraño J. Mass-length allometry covaries with ecosystem productivity at a global scale. Global Ecol Biogeogr. 2020;29:87-101. https://doi.org/10.1111/geb.13010 


\section{APPENDIX 1: REFERENCES OF SUPPORTING INFORMATION}

Berlese, A. (1905). Apparecchio: Per Raccogliere Presto E in Gran Numero Piccoli Arthropodi. Redia, 2, 85-90.

Bivand, R. S., Pebesma, E. J., \& Gómez-Rubio, V. (2013). Applied spatial data analysis with R. New York, NY: Springer.

Bjonstad, O. N. (2018). ncf: Spatial covariance functions. R package versión 1.2-5. Retrieved from https://CRAN.R-project.org/package=ncf

Bjornstad, O. N., \& Falck, W. (2001). Nonparametric spatial covariance functions: estimation and testing. Environmental and Ecological Statistics, 8, 53-70.

Cheverud, J. M. (1982). Relationships among ontogenetic, static, and evolutionary allometry. American Journal of Physical Anthropology, 59, 139-149.

Cock, A. G. (1966). Genetical aspects of metrical growth and form in animals. Quarterly Review of Biology, 41, 131-190.

Fusco, G., \& Minelli, A. (2013). Arthropod body segments and tagmata. In Minelli, A., Boxshall, G., \& Fusco, G. (Eds.), Arthropod biology and evolution. Molecules, development, morphology (pp. 197-221). Berlin, Germany: Springer.

Ganrud, C. (2016). DataCombine: Tools for easily combining and cleaning data sets. R package version 0.2.21. Retrieved from https://CRAN.Rproject.org/package $=$ DataCombine

Giuseppe, L., \& Maël, M. (2014). Perspectives on organisms. Lecture notes in morphogenesis (pp. 23-73). Berlin, Germany: Springer.

Hadley, N. F. (1994). Water relations of terrestrial arthropods (pp. 22-27). San Diego, CA: Academic Press.

Kerkhoff, A. J., \& Enquist, B. J. (2009). Multiplicative by nature: Why logarithmic transformation is necessary in allometry. Journal of Theoretical Biology, 257(3), 519-521.

Klingenberg, C. P. (1998). Multivariate allometry. In L. F. Marcus, M. Corti, A. Loy, G. J. P. Naylor \& D. E. Slice (Eds.), Advances in Morphometrics (pp. 23-49). New York, Plenum Press.

Klingenberg, C. \& Zimmermann, M. (1992). Static, ontogenetic, and evolutionary allometry: A multivariate comparison in nine species of water striders. The American Naturalist, 140(4), 601-620.

LaBarbera, M. (1989). Analyzing body size as a factor in ecology and evolution. Annual Review of Ecology, Evolution, and Systematics, 20, 97-117.

Legendre, P., \& Legendre, L. (1998). Numerical ecology (2nd ed., p. 853). Amsterdam, The Netherlands: Elsevier.

Moya-Laraño, J., Macías-Ordóñez, R., Blankehorn, W. U., \& FernándezMontraveta, C. (2008). Analysing body condition: Mass, volume or density? Journal of Animal Ecology, 77, 1099-1108.

Muller, W. (2001). Comparisons of mathematics education reform 100 years ago and today. The American Mathematical Monthly, 108, 126-143.

O'Hara, R. B., \& Kotze, D. J. (2010). Do not log-transform count data. Methods in Ecology and Evolution, 1(2), 118-122.

Reiss, M. J. (1989). The allometry of growth and reproduction (p. 182). Cambridge, UK: Cambridge University Press.

Rohlf, F. J. (2010). tpsDig. Stony Brook, NY: Department of Ecology and Evolution, State University of New York.

Tullgren, A. (1918). Ein sehr einfacher Ausleseapparat für terricole Tierfaunen. Zeitschrift für angewandte Entomologie, 4, 149-150.

Warton, D. I., Wright, I. J., Falster, D. S., \& Westoby, M. (2006). Bivariate line-fitting methods for allometry. Biological Reviews, 81(2), 259-291.

White, J. F., \& Gould, S. J. (1965). Interpretation of allometric equations. The American Naturalist, 99(904), 5-18.

\section{APPENDIX 2: DATA SOURCES}

Alford, D. V. (2008). Biocontrol of oilseed rape pest (p. 368). Oxford, UK: Wiley-Blackwell.
Beaver, D. L., \& Baldwin, P. H. (1975). Ecological overlap and the problem of competition and sympatry in the western and Hammond's flycatchers. The Condor, 77, 1-13.

Bon, A. (2016). Tout un monde dans mon jardín ... et au delà. French InfoJardin. Retrieved from http://unmondedansmonjardin.free.fr

Breymeyer, A. (1967). Correlations between dry weight of spiders and their length and fresh weight. Bulletin de L'Academie Polonaese des Sciences, XV, 263-265.

Clausen, I. H. S. (1983). Weight-length relations of eight species of spiders (Araneae) from Denmark. Entomologiske Meddelelser, 50, 139-144.

Díaz, J. A., \& Díaz, M. (1990). Estimas de tamaños y biomasas de artrópodos aplicables al estudio de la alimentación de vertebrados insectívoros. Doñana, Acta Vertebrata, 17, 67-74.

Edwards, R. L. (1996). Estimating live spider weight using preserved specimens. The Journal of Arachnology, 24, 161-166.

Edwards, R. L., \& Gabriel, W. L. (1998). Dry weight of fresh and preserved spiders (Araneida: Labidognatha). Entomological News, 109, 66-74.

Ganihar, S. R. (1997). Biomass estimates of terrestrial arthropods based on body length. Journal of Biosciences, 22, 219-224.

Gowing, G., \& Recher, H. F. (1984). Length-weight relationships for invertebrates from forests in south-eastern New South Wales. Australian Journal of Ecology, 9, 5-8.

Gruner, D. S. (2003). Regressions of length and width to predict arthropod biomass in the Hawaiian Islands. Pacific Science, 57, 325-336.

Henschel, J., Mahsberg, D., \& Stumpf, H. (1996). Mass-length relationship of spiders and harvestmen (Araneae and Opiliones). Revue Suisse de Zoologie, 1, 265-268.

Hódar, J. A. (1996). The use of regression equations for estimation of arthropod biomass in ecological studies. Acta Ecologica, 17, 421-433.

Höfer, H., \& Ott, R. (2009). Estimating biomass of Neotropical spiders and other arachnids (Araneae, Opiliones, Pseudoscorpiones, Ricinulei) by mass-length regressions. Journal of Arachnology, 37, 160-169.

Hopkin, S. (2019). University of Roehampton London. Centre for Research in Ecology, Evolution and Behaviour. Retrieved from http:// urweb.roehampton.ac.uk/collembola/taxonomy/, which have been copied from Steve Hopkin (deceased) personal website http://colle mbole.free.fr/www.stevehopkin.co.uk/index.html

Jarošik, V. (1989). Mass vs. length relationship for carabid beetles (Col., Carabidae). Pedobiologia, 33, 87-90.

Johnson, M. D., \& Strong, A. M. (2000). Length-weight relationships of Jamaican arthropods. Entomological News, 111, 270-281.

Klarner, B., Winkelmann, H., Krashevska, V., Maraun, M., Widyastuti, R., \& Scheu, S. (2017). Trophic niches, diversity and community composition of invertebrates top predators (Chilopoda) as affected by conversion of tropical lowland rainforest in Sumatra (Indonesia). PLoS ONE, 12(8), e0180915. https://doi.org/10.1371/journal.pone.0180915

Lang, A., Kroo $\beta$, S., \& Stumpf, H. (1997). Mass-length relationships of epigeal arthropod predators in arable land (Araneae, Chilopoda, Coleoptera). Pedobiologia, 41, 327-333.

Lebrun, P. (1971). Ecologie et biocěnotique de quelques peuplements d'arthropodes édaphiques (p. 204). Brussels: Institut Royal des Sciences Naturelles de Belgique.

Marcuzzi, G. (1987). The ratio weight/length in coleopterous insects. Elytron, 1, 17-23.

Mazantseva, G. P. (1975). Ratio of the body length and weight in Pachyiulus flavipes and Amblyiulus continentalis (Diplopoda, Juloidea). Zoologicheskii Zhurnal, 54, 1726-1729.

McLaughlin, O. B., Jonsson, T., \& Emmerson, M. C. (2010). Temporal variability in predator-prey relationships of a forest floor food web. Advances in Ecological Research, 42, 171-264.

Mercer, R. D., Gabriel, A. G. A., Barendse, J., Marshall, D. J., \& Chown, S. L. (2001). Invertebrate body sizes from Marion Island. Antartic Science, 13, 135-143.

Nentwig, W., Blick, T., Gloor, D., Hänggi, A. \& Kropf, C. (2019). Araneae. Spiders of Europe. Naturhistorisches museum Bern, 
Arachnologische Gesellschaft, British Arachnological Society, Czech Arachnological Society, Association Française d'Arachologie (AsFra), European Society of Arachnology, Schwizerische Eidgenossenschaft Confédération suisse, SPIDOnet.gr and Università Degli Studi di Torina. Retrieved from https://araneae.nmbe.ch

Newton, J. S., \& Proctor, H. (2013). A fresh look at weight-estimation models for soil mites (Acari). International Journal of Acarology, 39, 72-85.

Palacios-Vargas, J. G. \& Salazar-Martínez, A. (2014). A new species of Tullbergia (Collembola, Tullbergiidae) from Buenos Aires, Argentina. ZooKeys, 416(416), 23-30.

Petersen, H. (1975). Estimation of dry weight, fresh weight, and calorific content of various Collembolan species. Pedobiologia, 15, 222243.

Richardson, B. A., Richardson, M., Scatena, F. \& Mcdowell, W. (2000). Effects of nutrient availability and other elevational changes on bromeliad populations and their invertebrate communities in a humid tropical forest in Puerto Rico. Journal of Tropical Ecology, 16, 167-188.

Rogers, L. E., Buschbom, R. L., \& Watson, C. R. (1977). Length-weight relationship of shrub-steppe invertebrates. Annals of the Entomological Society of America, 70, 51-53.

Roy, H., \& Comont, R. (2019). UK beetle recording. Biological Records Centre, Joint Nature Conservation Committee, UK-SCAPE and Centre for Ecology \& Hydrology of Natural Environment Research Council. Recovered from: www.coleoptera.org.uk

Sabo, J. L., Bastow, J. L., \& Power, M. E. (2002). Length-mass relationships for adult aquatic and terrestrial invertebrates in a California watershed. Journal of the North American Benthological Society, 21, 336-343.

Sage, R. D. (1982). Wet and dry-weight estimates of insects and spiders based on length. American Midland Naturalist, 108, 407.

Sample, B. E., Cooper, R. J., Greer, R. D., \& Whitmore, R. C. (1993). Estimation of insect biomass by length and width. American Midland Naturalist, 129, 234-240.

Santos-Gómez, A. (2013). Indicating assemblage vulnerability and resilience in the face of climate change by means of adult ground beetle length-weight allometry over elevation strata in Tenerife (Canary Islands). Ecological Indicators, 34, 204-209.

Schoener, T. W. (1980). Length-weight regressions in tropical and temperate forest-understory insects. Entomological Society of America, 73, 106-109.

Shinohara, K., Higa, Y., \& Niijima, K. (2007). Postembryonic development of Trigoniulus corallinus (Gervais) (Diplopoda: Spirobolida, Pachybolidae). Edaphologia, 82, 9-16.

Sokoloff, A., Sirotnik, B., \& Beeman, C. (1999). Length and weight in Tribolium brevicornis Le Conte. Tribolium Information Bulletin, 39, 343-345.

Tanaka, M. (1970). Ecological studies on communities of soil Collembola in Mt. Sobo, Southwest Japan. Japanese Journal of Ecology, 20, 102-110.

Van Duinen, J. J. (2009-2018). Site over natuur, tuin, katten en voorouders. Order: Opiliones, Harvestmen. Retrieved from http://www. janvanduinen.nl/opilionesengels.php

VanDyk, J. (2003-2019). BugGuide. Identification, Images \& Information for Insects, Spiders \& Their Kin for the United States \& Canada. lowa State University. Department of Entomology. Retrieved from https ://bugguide.net

Van Straalen, N. M. (1989). Production and biomass turnover in two populations of forest floor Collembola. Netherlands Journal of Zoology, 39, 156-168.

Vannier, G. (1973). Relations dimesionnellement homogènes entre la taille, la surface et le poids des individus de l'espèce Allacma fusca (L.), Insecte Collembole. Revue d'Ecologie et de Biologie, 10, 559-573.

Voigtländer, K. (2000). Comparative studies of the post-embryonic development in Lithobius-species (Chilopoda, Lithobiidae). Mitteilungen der Deutschen Gesellschaft fuer Allgemeine und Angewandte Entomologie, 12, 535-540.

Voigtländer, K. (2007). The life cycle of Lithobius mutabilis L. Koch, 1862 (Myriapoda: Chilopoda). Bonner Zoologische Beitraege, 55, 9-25.

Wardhaugh, C. W. (2013). Estimation of biomass from body length and width for tropical rainforest canopy invertebrates. Australian Journal of Entomology, 52, 291-298. 